\title{
Anomalia congênita em vasos da base do coração de um potro
}

\author{
Gisele Fabrino MACHADO ${ }^{1}$ \\ Cinthia Graziela \\ CANDIOTO ${ }^{1}$ \\ Roberto CARVALHAL ${ }^{2}$ \\ Rosemeri de Oliveira \\ VASCONCELOS ${ }^{1}$ \\ Edson Francisco do \\ ESPÍRITO SANTO ${ }^{1}$ \\ Daniela BOAVENTURA DE \\ OLIVEIRA $^{1}$ \\ Correspondência para: \\ GISELE FABRINOMACHADO \\ Faculdade de Medicina Veterinária \\ Universidade Estadual Paulista \\ Rua Clóvis Pestana, 793 \\ Jardim Dona Amélia \\ 16050-680 - Araçatuba - SP \\ giselem@fmva.unesp.br
}

Recebido para publicação: 13/07/2004 Aprovado para publicação: 28/03/2005

1 - Departamento de Clínica, Cirurgia e Reprodução Animal da Universidade Estadual Paulista, Araçatuba - SP

2 - Departamento de Apoio, Produção e Saúde Animal da Universidade

Estadual Paulista, Araçatuba - SP

\begin{abstract}
Resumo
Anomalias congênitas do coração e de grandes vasos estão entre as mais comuns encontradas em animais, porém são raras em eqüinos. Este relato descreve uma anomalia cardíaca que apresenta confluência entre a parede da aorta e do tronco pulmonar, ramificação da veia cava caudal no átrio esquerdo com presença de válvula e conseqüentemente posição errônea do coração na cavidade torácica de um potro da raça Quarto-de-Milha encontrado morto após o nascimento. O diagnóstico foi realizado pela associação dos achados macroscópicos durante a necrópsia e o exame histopatológico realizados no Curso de Medicina Veterinária- UNESP-Araçatuba.
\end{abstract}

\section{Introdução}

Distúrbios congênitos do coração e grandes vasos enquadram-se entre as anomalias mais freqüentemente encontradas em animais, porém são raras em eqüinos ${ }^{1,2,3}$. Embora alguns defeitos sejam herdados como traços poligênicos, em geral, a causa dos defeitos cardiovasculares não é conhecida. As conseqüências dos defeitos que permitem o desvio de sangue dependem da direção do fluxo: se da direita para a esquerda, ou vice-versa ${ }^{1}$. Com o passar do tempo os desvios da esquerda para a direita levam a uma hipertensão pulmonar, hipertrofia do ventrículo direito, já a inversão do fluxo da direita para a esquerda, leva a anóxia dos tecidos ${ }^{1}$. A aorta é o principal tronco arterial sistêmico ${ }^{4}$. Ela tem início na base do ventrículo esquerdo e é quase mediana em sua origem ${ }^{4}$. Sua primeira parte, a aorta ascendente, passa dorsal e cranialmente entre o tronco pulmonar, à esquerda, e o átrio direito à direita ${ }^{4}$. A seguir curva-se acentuadamente caudalmente e dorsalmente, inclina-se um tanto para a esquerda, formando o arco da aorta ${ }^{4}$. O tronco braquiocefálico está direcionado cranialmente e um tanto dorsalmente no mediastino cranial, ventralmente à traquéia ${ }^{4}$. Oposto à primeira costela ele emite o tronco bicarotídeo, a artéria subclávia direita ${ }^{4}$. O tronco pulmonar está relacionado cranialmente à aurícula direita, caudalmente à aurícula esquerda e medialmente a aorta ascendente ${ }^{4}$ Está envolto, com a aorta ascendente, numa bainha comum da lâmina visceral do pericárdio seroso ${ }^{4}$. Próximo da bifurcação está ligado ao arco da aorta por uma faixa fibrosa de aproximadamente 1,2cm de largura; este é o ligamento arterial, um remanescente do grande ducto arterial, que conduz a maior parte do sangue oxigenado do tronco pulmonar até a aorta descendente do feto ${ }^{4}$. A maior parte do átrio direito forma uma câmara (seio venoso), onde desembocam as principais veias sistêmicas ${ }^{5}$. A veia cava caudal entra na parte caudodorsal e a veia cava cranial na parte craniodorsal desta câmara ${ }^{5}$. O átrio esquerdo recebe as veias pulmonares, que entram, separadamente ou em grupos, em 2 ou 3 locais: craniossinistro, craniodextro e, em algumas espécies, caudal ${ }^{5}$.

\section{Materiais e Métodos}

Potro, macho, da raça Quarto-de- 
Milha, encontrado morto no piquete a aproximadamente $10 \mathrm{~m}$ do local de parto, o qual ocorreu dentro do tempo considerado normal. Encaminhado ao Serviço de Patologia da Medicina Veterinária, FOAraçatuba para a realização de exames de necropsia e histopatológico de rotina. Os tecidos foram fixados em formalina tamponada a $10 \%$, processados na rotina do laboratório, cortados em $5 \mathrm{~mm}$ e corados com hematoxilina e eosina.

\section{Resultados e Discussão}

À necropsia observou-se anomalia em vasos da base do coração e errôneo posicionamento do mesmo na cavidade torácica. $\mathrm{O}$ ápice do coração estava voltado cranialmente, o ventrículo direito dorsalmente, promovendo uma alteração do tronco braquiocefálico que estava direcionado dorso-caudalmente no mediastino cranial, ventralmente à traquéia. O seio transverso do coração possuía sentido átrio direito-átrio esquerdo ao invés de átrioventrículo. O coração foi examinado segundo a técnica descrita por Jones ${ }^{6}$. Observamos que a aorta se iniciava na base do ventrículo esquerdo e sua origem não era mediana, mas sim voltada para o átrio direito, ou seja, em direção ao antímero direito. A aorta ascendente, ao deixar o ventrículo esquerdo apresentava redução de $2 / 3$ do seu calibre quando comparado ao do arco aórtico normal (Figura. 1- F). Além disto, ao corte, no local onde deveria existir o ducto arterioso, observamos que havia um ramo da artéria pulmonar que se comunicava diretamente com a aorta (Figura. 1- G). Neste ponto foi possível observar também espessamento da parede do vaso, quando comparado com porções distais da aorta (Figura. 1- E).

O tronco braquiocefálico se ramificava em artéria subclávia esquerda e artéria subclávia direita, a qual possuía maior calibre. Da artéria subclávia esquerda originava-se um tronco que se ramificava em artéria costocervical e vertebral direita. As artérias coronárias direita e esquerda surgiam dos seios coronários direito e esquerdo, respectivamente, idêntico ao coração normal. A musculatura ventricular esquerda e direita apresentava-se hipertrofiada e no átrio esquerdo havia fibroelastose (Figura. 3- C). No exame externo do coração havia somente uma desembocadura da veia cava caudal, igual ao existente no coração normal, entretanto, ao abrirmos este vaso, notamos que o mesmo possuía uma ramificação tanto no átrio direito quanto no átrio esquerdo, resultando em comunicação interatrial no local onde estaria localizado o forame oval (Figura. 2). A parede do segmento da veia cava caudal que desembocava no átrio esquerdo apresentava-se inserida na parede dorsal deste e, na porção ventral do óstio de desembocadura emergiam cordas tendíneas, as quais se inseriam no endocárdio da região e apresentavam características semelhantes à de uma válvula átrio ventricular. (Figura. 3- A). Os demais órgãos examinados não apresentaram alterações macroscópicas significativas.

No exame microscópico do fígado observou-se necrose e extensa hemorragia centrolobular. O pulmão, que apresentou docimasia positiva, apresentava-se congesto. Embora houvesse lóbulos com atelectasia, a maior parte apresentava alvéolos preenchidos por ar e ruptura de paredes alveolares. No exame do miocárdio dos átrios e ventrículos observamos células com núcleos grandes, irregulares, com nucléolos evidentes e cromatina frouxa.

Dentre as anomalias cardíacas em eqüinos, há relatos de defeito septal subaórtico, defeito septal ventricular e malformações que incluíam aorta, valvas pulmonares e artéria pulmonar ${ }^{3,7}$. Não encontramos citação na literatura que relatasse a presença de anomalias cardíacas em eqüinos da raça Quarto-de-Milha. Também não há citação do conjunto de anomalias aqui descrito em eqüinos ou em outras espécies onde há maior incidência de defeitos congênitos do coração (persistência do ducto arterioso, estenose de pulmonar, 


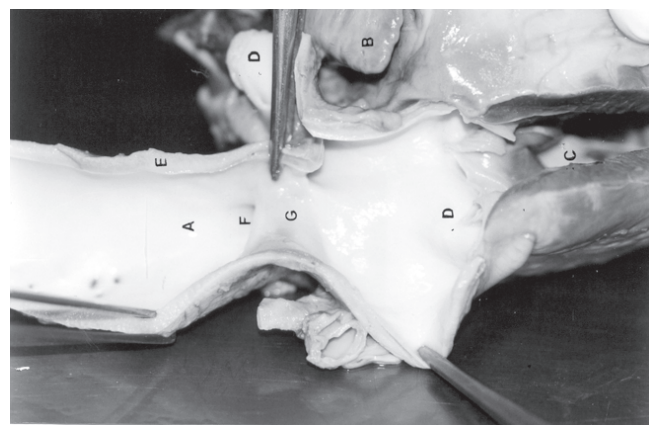

Figura 1 - Face auricular de coração de potro natimorto: A- aorta ascendente; B-átrio esquerdo; C-ventrículo direito; D-aorta pulmonar; E- espessamento da parede da aorta; F-óstio da aorta; G- comunicação da aorta com a artéria pulmonar

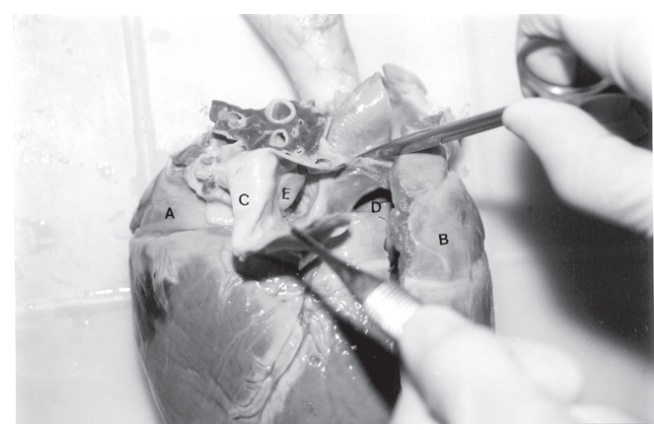

Figura 3 - Face auricular de coração de potro natimorto: A-válvula da veia cava caudal em átrio esquerdo; B- ventrículo esquerdo C-fibroelastose em átrio esquerdo

estenose subaórtica, persistência do arco do septo atrial, defeitos do septo ventricular, transposição das artérias aorta e pulmonar, hematomas valvulares e defeitos do coxim endocárdico ${ }^{8}$ ).

No caso aqui descrito, o errôneo posicionamento do coração ocorreu devido à conexão e o posicionamento arterial e venoso anormal. O aumento da capacidade de trabalho dos ventrículos quando há aumento do enchimento, ou aumento da resistência arterial, é possível até certo ponto, a partir do qual o débito cardíaco diminui ${ }^{9}$. Isto resulta em uma sobrecarga crônica, a uma queda geral da função e a um aumento do volume cardíaco9. Quando há um constante aumento na carga, aumenta a quantidade de miofibrilas, mitocôndrias e de enzimas glicolíticas nas fibras musculares, causando a hipertrofia de ambos ventrículos? No local de confluência entre a aorta e o

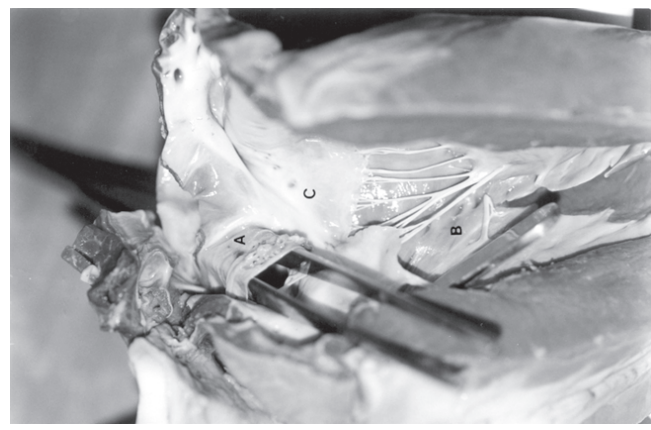

Figura 2 - Face atrial de coração de potro natimorto: A-átrio esquerdo; B-átrio direito; C-óstio da veia cava caudal; D-óstio da veia cava caudal no átrio direito; E-óstio da veia cava caudal no átrio esquerdo com válvula

tronco pulmonar, ocorre desvio de sangue da circulação venosa para a arterial resultando em sangue com baixa oxigenação o qual é distribuído para os tecidos. Isto também acontece no átrio esquerdo, que deveria receber sangue arterial oriundo dos pulmões pelas veias pulmonares, e que neste caso recebe também sangue venoso através da desembocadura de um ramo da veia cava caudal que tem comunicação interna com o átrio. Em resposta a este estímulo, observamos a presença de fibroelastose. Dessa maneira, o sangue que deixa o ventrículo esquerdo pela aorta já apresenta baixa oxigenação. Nas comunicações intercavitárias há passagem de sangue no sentido da câmara que tem menor pressão sangüínea ${ }^{10}$. Pela disposição das cordas tendíneas da válvula anômala observada na veia cava caudal, concluímos que durante a contração atrial, não há possibilidade de retorno sangüíneo do átrio esquerdo para a veia cava caudal, o que resulta em aumento do fluxo sangüíneo que chega ao átrio e ventrículo esquerdos. A redução do calibre da aorta ascendente aumenta a resistência sistólica e ocorre acúmulo de sangue no ventrículo, contribuindo para o aumento da pressão intracavitária.

A fibroelastose representa uma resposta inespecífica do endocárdio, mais intensa quanto mais imaturo o coração ${ }^{10}$, provavelmente em resposta ao aumento de pressão intracavitária. O endocárdio se torna espessado por camadas de tecido fibroso e 
elástico, dando à superfície endocardíaca um aspecto brilhoso, branco e prateado ${ }^{1}$.

Existem diferenças significativas entre a circulação fetal e neonatal. Portanto, defeitos que são inaparentes no feto podem se tornar muito importantes no neonato. Durante a vida fetal, o coração e o encéfalo recebem $80 \%$ do sangue oxigenado através da placenta. Após o nascimento, a oxigenação do sangue passa a ser realizada nos pulmões. No caso em questão, onde constatamos anomalias que resultaram na mistura de sangue arterial e venoso, a sobrevida e o desenvolvimento do animal fatalmente estariam comprometidos. Poucos autores relatam a sobrevivência de potros com anomalias cardíacas, sendo a maioria dos relatos achados necroscópicos ${ }^{1}$. Concluímos que neste caso, o suprimento de sangue através das coronárias não apresentava oxigenação suficiente para a nutrição do miocárdio hipertrofiado, resultando na morte do animal logo após o parto.

\title{
Congenit anomaly in vessels of base in a foal heart
}

\begin{abstract}
Congenital anomalies of heart and large vessels are among more common found in animals, however rare in horses. This survey describes a cardiac anomaly that presents confluence between aorta wall and lung trunk, ramification of caudal cava vein in left atrium with presence of valve and consequently erroneous position of heart in thoracic cavity of one foal found dead after birth. The diagnostic was carried out for macroscopic finds association during the necropsy and histopathologic exams carried out at School of Veterinary Medicine - Unesp Araçatuba.
\end{abstract}

\section{Referências}

1 JONES, T. C.; HUNT, R. D.; KING, N. W. Patologia veterinária. 6. ed. São Paulo: Manole, 2000. p. 991995.

2 BLOOD, D. C.; HENDERSON, J. A. Veterinary medicine. 4. ed. London: Ballière Tindall, 1974. p. 143.

3 ROONEY, J. R.; FRANKS, W. C. Congenital cardiac anomalies in horses. Veterinary Pathology, v. 1 p.4544641964.

4 GETTY, R. Anatomia dos animais domésticos: v. 15. ed. Rio de Janeiro: Guanabara Koogan, 1986. p. 518531.

5 DYCE, K. M.; SACK, W.; WENSING, C. J. G. Tratado de anatomia veterinária. 2. ed. Rio de Janeiro: Guanabara Koogan, 1997. p. 175.

6 JONES, T. C.; GLEISER, C. A. Veterinary necropsy procedures. Philadelphia: J. B. Lippincott Company, 1954.

7 BAYLY, W. M. et al. Multiple congenital heart anomalies in five Arabian foals. J Am Vet Med Assoc, v. 181, p.684-689. 1982.

8 CARLTON, W. W.; MCGAVIN, M. D. Patologia veterinária especial de THOMSON. 2. ed. São Paulo: Artmed, 1998. p. 201.

9 KOLB, E.; GÜRTLER, H.; KETZ, H. A.; SCHRÖDER, L.; SEIDEL, H. Fisiologia veterinária. 4. ed. Rio de Janeiro: Guanabara Koogan, 1984. p. 265.

10 Brasileiro Filho,G. Bogliolo patologia. 6. ed. Rio de Janeiro: Guanabara Koogan, 2000. p. 349-375. 